\title{
O desafio de processos participativos nas atividades de Educação Ambiental no Arquipélago de Fernando de Noronha - PE - Brasil ${ }^{1}$
}

\author{
The Challenge of participatory processes in Environmental Education activities in the \\ Fernando de Noronha Archipelago - PE - Brazil
}

\section{El desafío de procesos participativos en las actividades de Educación Ambiental en el Archipiélago de Fernando de Noronha - PE - Brasil}

\author{
Vivian Battaini ${ }^{2}$ \\ Marcos Sorrentino ${ }^{3}$ \\ José Martins da Silva Júnior ${ }^{4}$
}

\begin{abstract}
Resumo
O artigo traz reflexões sobre o desafio de promover processos participativos em atividades de Educação Ambiental (EA). Apoiado em pesquisa qualitativa realizada em Fernando de Noronha, identifica a relação entre os documentos oficiais e a EA e a participação; mapeia as atividades de EA desenvolvidas no Arquipélago em 2013 e categoriza as técnicas voltadas à participação. Os principais resultados são: necessidade de institucionalizar políticas públicas de EA; importância de ambientalização e enraizamento da EA nas instituições; timidez com que as atividades têm contribuído para a formação de sujeitos participativos. Por fim, considera-se que o desenvolvimento de processos participativos fomentados pelas atividades de EA na Ilha pode contribuir para a formação de pessoas comprometidas com a melhoria das condições socioambientais de seu território e com a cidadania planetária.
\end{abstract}

Palavras-chave: Educação Ambiental. Participação.Fernando de Noronha.

\begin{abstract}
The article brings reflections regarding the challenge to promote participative process in enviromental education activties. Supported by a qualitative research issued in Fernando de Noronha it was possible to identify the

1 Esse texto é desdobramento da tese de doutorado "Educação Ambiental e políticas públicas em Fernando de Noronha: a participação na construção de escolas e sociedades sustentáveis" elaborada pela autora principal sob orientação do segundo autor do presente artigo e defendida em 2017 junto ao Programa de Pós Graduação Interunidades em Ecologia Aplicada da Universidade de São Paulo (USP), campus de Piracicaba. A pesquisa só foi possível pela parceria com o Projeto Golfinho Rotador de Fernando de Noronha/Pernambuco, Brasil, financiado pela Petrobrás, no qual o terceiro autor é fundador e que a primeira autora atuou como educadora ambiental no ano de 2013.

${ }^{2}$ Bióloga (Universidade Estadual Paulista Júlio de Mesquita Filho). Doutora e Mestre em Ciências - Programa Ecologia Aplicada (ESALQ/CENA, 2017; 2011). Pesquisadora do Laboratório de Educação e Política Ambiental (Oca - ESALQ/USP, 2010 - 2019). Membra da Equipe Pedagógica da Especialização Educação Ambiental e Transição para Sociedades Sustentáveis (Oca - ESALQ/USP). Educadora Ambiental do Fundo Brasileiro de Educação Ambiental. vivian_battaini@yahoo.com.br

${ }^{3}$ Pedagogo, biólogo e ambientalista. Professor sênior da USP, campus de Piracicaba. Foi diretor de EA do Ministério do Meio Ambiente da República Federativa do Brasil, de 2003 a 2008. Coordenador do Laboratório de Educação e Política Ambiental (Oca - ESALQ/USP). sorrentino.ea@gmail.com

${ }^{4}$ Graduado em Oceanografia Biológica e em Oceanografia Geológica pela Fundação Universidade Federal do Rio Grande (1988), com mestrado (1996) e doutorado (2005) no Programa de Pós Graduação em Oceanografia Biológica da Universidade Federal de Pernambuco. Atualmente é Analista Ambiental do Instituto Chico Mendes de Conservação da Biodiversidade (ICMBio), lotado no Núcleo de Gestão Integrado de Fernando de Noronha do ICMBio. Criou em 1990 o Projeto Golfinho Rotador (www.golfinhorotador.org.br). josemartinstk@gmail.com
\end{abstract}


relation of official documents with environmental education and participation, environmental education activities in the archipelago in 2013 and categorize the technics used on participation.The main results are: the necessity of institutionalize EE public policies, importance of environmentalization and enrooting of EE in institutions, and the slowness that activities have been contributed to the formation of participative individuals. Thus, it's considered that the development of the participative process fomented by the activities of EE in the island may contribute to formation of committed individuals with their own territory and the worldwide citizenship.

Keywords: Environmental Education. Participation. Fernando de Noronha.

\section{Resumen}

El artículo trae reflexiones sobre el desafío de promover procesos participativos en actividades de Educación Ambiental (EA). Apoyado en investigación cualitativa realizada en Fernando de Noronha, identifica la relación entre los documentos oficiales y la EA y la participación; se asigna las actividades de EA desarrolladas en el Archipiélago en 2013 y categoriza las técnicas dirigidas a la participación. Los principales resultados son: necesidad de institucionalizar políticas públicas de EA; importancia de ambientalización y enraizamiento de la EA en las instituciones; timidez con que las actividades han contribuido a la formación de sujetos participativos. Por último, se considera que el desarrollo de procesos participativos fomentados por las actividades de EA en la Isla puede contribuir a la formación de personas comprometidas con la mejora de las condiciones socioambientales de su territorio y con la ciudadanía planetaria.

Palabras clave: Educación ambiental. Participación. Fernando de Noronha.

\section{Ponto de partida: bases teóricas da Educação e da Educação Ambiental}

O presente artigo dialoga com vertentes de educação comprometidas com a transformação da sociedade, focando no desenvolvimento da criticidade, autonomia e emancipação dos sujeitos. Essas concepções podem ser nomeadas como educação progressista (LIBÂNEO, s/d, p. 21).

Os trabalhos de Paulo Freire reforçam a importância da autonomia dos educandos (FREIRE, 2000) na leitura do mundo, enfatizando que o processo de ensino-aprendizagem deve partir da realidade dos estudantes (FREIRE, 1981), reconhecendo o local em que se vive para ser capaz de transformá-lo.

$\mathrm{O}$ fortalecimento dos indivíduos, para que sejam protagonistas de suas vidas e de seu território, exige que os sujeitos sejam considerados em sua totalidade, conectando suas diversas dimensões (cognitiva, afetiva, ética, social, lúdica, estética, biológica, espiritual). O que pode-se chamar de educação integral, caracterizada "pela ideia de uma formação 'mais completa possível' para o ser humano" (MOLL, 2009, p.15).

Edgar Morin (2006) contribui com o debate sobre educação integral ao propor caminhos para o fortalecimento dos processos de ensino-aprendizagem por meio de sete saberes necessários à educação do futuro: um conhecimento capaz de criticar o próprio conhecimento, discernir as informações-chave, tendo claros os princípios do conhecimento pertinente; as cegueiras do conhecimento; os princípios do conhecimento pertinente; ensinar a condição humana; ensinar a identidade terrena; ensinar a enfrentar as incertezas; ensinar a compreensão.

Ensinar a condição humana relaciona-se à compreensão da complexidade terrena e do reconhecimento de uma identidade humana planetária, ao mesmo tempo em que respeita a diversidade cultural existente. Para Morin (2006, p.55), "todo desenvolvimento verdadeiramente humano significa o desenvolvimento conjunto das autonomias individuais, das participações comunitárias e do sentimento de pertencer à espécie humana".

Alguns pesquisadores inspirados em concepções progressistas de educação enunciam cinco conceitos como fundamentação teórica para o direcionamento de práticas no campo da 
Educação Ambiental: identidade, comunidade, diálogo, potência de ação e felicidade (ALVES et al., 2010).

Evidencia-se a relação das atividades educadoras com o conceito de potência de ação, entendido como a participação que relaciona-se "ao encontro com o outro e o desejo de participar não vem de fora, e sim, conforme Espinosa, é uma necessidade natural do sujeito, uma busca pela liberdade e pela felicidade independentemente de obrigação ou moralidade" (ALVES et al. 2010,p.26). Nessa direção, a Educação Ambiental pode contribuir para que os indivíduos se encontrem consigo mesmos e com os outros, e se potencializem para agir.

Essa visão de EA é uma entre outras que dialogam ou disputam espaço na sociedade. Distintos autores, entre eles Reigota (1998), Sorrentino (2001), Andrade et al. (2014), e um estudo a partir dos dados do censo escolar brasileiro (VEIGA; AMORIM; COSSÍO, 2005), têm apontado o amadurecimento da Educação Ambiental no Brasil.

Historicamente, tem havido um ganho de qualidade na educação ambiental (EA) brasileira, que se reflete no nível de organização da mesma dentro do país. Esse ganho é percebido na trajetória da EA no Brasil, que evolui de um contexto inicial de realização de ações pontuais espacial e temporalmente, para o estabelecimento de parcerias não formais (redes) e organização de projetos e programas de EA. Surgem, assim, ações mais concertadas e estruturadas envolvendo sinergia entre atores e com caráter temporal mais prolongado (ANDRADE et al., 2014, p. 824).

Entre os fatores que contribuíram para a ampliação e qualificação da EA está a construção de políticas públicas nacionais, estaduais, regionais, setoriais e municipais. Destaque para a Política Nacional de Educação Ambiental (PNEA) e o Programa Nacional de Educação Ambiental (ProNEA), influenciados pelo Tratado de Educação Ambiental para Sociedades Sustentáveis e Responsabilidade Global.

O Tratado foi construído por educadores ambientais do mundo todo, no processo preparatório e durante o Fórum Internacional de Organizações Não Governamentais e Movimentos Sociais, na Rio 92. Ele traz princípios filosóficos para o desenvolvimento da EA no planeta. A PNEA expressa o direito constitucional de acesso de todos os cidadãos à EA, e permitiu a sua capilarização no território nacional. O ProNEA (BRASIL, 1997, 2003, 2005, 2014) determinou diretrizes, princípios, missão, objetivos, linhas de ação e estrutura organizacional da EA no país.

A PNEA e o ProNEA trazem, em seu conteúdo, a necessidade de incentivo à participação individual e coletiva (BRASIL, 1999, art. 4), bem como o foco da Educação Ambiental em ações que promovam a participação (BRASIL, 1999, art. 13) para a "construção de valores culturais comprometidos com a qualidade ambiental e a justiça social; e de apoio à sociedade na busca de um modelo socioeconômico sustentável" (BRASIL, 2014, p.24).

A participação é enunciada, em diversos documentos, como essencial para processos educadores comprometidos com transformações sociais. O que leva ao questionamento: o que é participação e qual a sua relação com a educação?

\section{Participação em foco}

De acordo com Pedro Demo (1996, p. 18)“dizemos que participação é conquista para significar que é um processo, no sentido legítimo do termo: infindável, em constante vir-a-ser, sempre se fazendo".

Para Juan Díaz-Bordenave (1994, p. 16) a participação é composta por duas bases: a afetiva - "participamos porque sentimos prazer em fazer coisas com os outros" e a instrumental - "participamos porque fazer coisas com outros é mais eficaz e eficiente que fazê-las sozinhos". 
Para Marcos Sorrentino (2001, p. 219), o conceito de participação relaciona-se aos de pertencimento, emancipação, identidade, comunidade, dentre outros. O indivíduo se mobiliza a participar quando se sente pertencente a algo ou que algo lhe pertence, o pertencimento emerge como oposto à alienação. A possibilidade de intervenção em um espaço se amplia quando o indivíduo o conhece, o que remete à "noção de identidade [que $]^{5}$ está relacionada à capacidade de visualizar o espaço e o tempo onde se está inserido".

Bader Burihan Sawaia (2001, p.131) defende que "as propostas de participação devem alimentar bons encontros, com profundidade emocional e continuidade no tempo, mas atuando no presente, para evitar a responsabilidade abstrata do cidadão". A autora enfatiza a necessidade de valorização do momento da participação e não apenas das consequências que ela pode promover. O estar presente, fazer junto e compartilhar são especiais e transformadores.

A participação se materializa nas microparticipações e macroparticipações. A primeira orienta-se por reivindicações específicas em "comunidades, sindicatos, associações de bairro, grêmios estudantis, sociedades profissionais, grupos de igreja, clubes esportivos, escolas de samba e muitas outras expressões associativas" (DÍAZ-BORDENAVE, 1994, p.57). A microparticipação prepara para as macroparticipações, aquelas que envolvem a sociedade em níveis mais amplos.

Díaz-Bordenave (1994) classifica os níveis de participação em informativo, consultivo, corresponsável, assessorado e autogestionado. O menor grau de participação ocorre no nível informativo, no qual a preocupação é disponibilizar informações. No nível mais alto, a autogestão, seus membros definem "objetivos, escolhem seus meios e estabelecem os controles pertinentes, sem referência a uma autoridade externa" (DÍAZBORDENAVE, 1994, p. 32).

Soma-se ao nível de participação a importância das decisões às quais os membros têm acesso. Sorrentino (2000, p. 102) evidencia a necessidade de "definir quais são os limites de representatividade, mas, mais do que isso, precisamos definir quais os limites de decisão para cada assunto e para cada grupo". Além disso, o autor apresenta cinco dimensões essenciais para viabilizar a participação: infraestrutura básica, disponibilização de informações, existência de espaços de locução e de tomada de decisão compartilhada e subjetividade. Com relação à subjetividade, afirma que "não há participação sem que as pessoas se sintam comprometidas, envolvidas com aquela situação" (SORRENTINO, 2000,p. 102).

Independentemente de qual for o processo participativo, eles proporcionam, em diferentes graus, um aprendizado individual e social. Demo (1996, p. 27)aponta a "questão do acesso universalizado a um mínimo de educação formal, como instrumentalização preliminar para o exercício da cidadania"; sendo um instrumento de participação decisivo, DíazBordenave (1994, p.56-57) enfatiza a função educativa dos processos participativos.

Por sua vez, Macpherson (1978 apud PATEMAN, 1992, p. 142) afirma que

[...]a participação é educativa e promove, por um processo de capacitação e conscientização (individual e coletiva), o desenvolvimento da cidadania, cujo exercício configura-se como requisito central na ruptura com o ciclo de subordinação e de injustiças sociais. Com efeito, a participação conferiria um outro ciclo (virtuoso) ancorado nas relações entre participação cidadã, mudança da consciência política e redução das desigualdades sociais.

$\mathrm{Na}$ visão dos ambientalistas, especialmente os da América Latina, a participação enfatiza "a questão educacional, debatendo liberdades democráticas e modelos de gestão como administrar nossos espaços comuns, desde os micro espaços cotidianos na família, na casa, no bairro etc. até o planeta" (SORRENTINO, 2000, p. 98).

\footnotetext{
${ }^{5}$ Os colchetes referem-se à introdução de palavra ou texto por parte dos autores do presente artigo.
} 


\section{Algumas conexões entre participação, Educação Ambiental, escola e território}

O interesse de pesquisadores sobre os aspectos da participação implicados em educação, no Brasil, tornou-se marcante a partir dos anos 1980 (GHANEM, 2004, p.163). Venera $(2009$, p. 232) elenca os documentos que trazem a participação de todos e, também, destacam a liberdade, autonomia e postura crítica que orientam a construção da cidadania, entre eles: Constituição Federal (1988), constituições estaduais; indicações internacionais pós Declaração de Jomtien, (1990); Lei de Diretrizes e Bases da Educação Nacional, (1996); Parâmetros Curriculares Nacionais (1997).

Alguns autores como Faundez (1993), Demo (1996), Cabral (2007) e Gadotti (2015) defendem a participação nos processos de ensino-aprendizagem, reforçando seu potencial para a aprendizagem política, gestão democrática, criação de uma nova pedagogia e exercício da cidadania. Correia (2001, apud GHANEM, 2004, p.172), Antunes (2011) e a Declaração Mundial de Educação Para Todos (1990) relacionam a maior participação com a melhoria da qualidade da Educação.

Segundo Gadotti (2015, p. 5), "pode-se dizer que a participação e a autonomia compõem a própria natureza do ato pedagógico. A participação é pressuposto da própria aprendizagem”. Para Demo (1996, p. 49), “a maior virtude da educação, ao contrário do que muitos pensam, está em ser instrumento de participação política".

Segundo estudos de Ghanem (2004, p. 166) sobre a participação na unidade escolar, a integração entre escola, família e comunidade precisa ser entendida "como representação e participação política". Nove promotores da participação da comunidade na escola foram propostos por Andrews (1999, apud GHANEM, 2004, p.168): informação, trabalho em equipe, foco na família, conhecimento da comunidade, criatividade, respeito, disciplina, responsabilidade e liderança escolar.

Porém, parte das pesquisas apontam dificuldades e limitações para efetivar espaços e momentos participativos na unidade escolar (PARO, 1995, apud GHANEM, 2004) relacionados aos condicionantes internos (materiais, institucionais, político-sociais e ideológicos) e externos à unidade escolar (econômico-sociais, culturais, institucionais). Tais pesquisas podem ser utilizadas para refletir sobre propostas que visem o enfrentamento das dificuldades e o consequente fortalecimento da participação. Além de visualizar a importância da participação da comunidade escolar, é essencial evidenciar que, de modo isolado, apenas a participação não basta para solucionar os desafios da escola e do seu território.

Pressupõe-se que a Educação Ambiental apresente características que podem contribuir no processo de fortalecimento da participação. Dentre essas características, destacam-se quatro: caráter transdisciplinar, dialógico, voltado à formação de sujeitos autônomos e protagonistas de suas vidas, e focada numa formação integral.

Para concretização dos objetivos, as temáticas transdisciplinares exigem a integração das diferentes disciplinas e profissionais; o exercício do diálogo proporciona um aprendizado importante para processos participativos; o fomento à autonomia contribui com a formação de sujeitos capazes de participar ativamente nos processos dos quais fazem parte; por fim, a formação integral fomenta o autoconhecimento, fortalecendo o indivíduo enquanto sujeito capaz de auxiliar as transformações em sua vida.

Soma-se a isso o fato que a EA "elimina fronteiras entre escola e comunidade, ao tomar como eixo do trabalho pedagógico a problemática socioambiental" (JACOBI; TRISTÃO; FRANCO, 2009, p.70).

Além disso:

Uma das funções mais importantes da escola é seu poder de influência e transformação da comunidade em que está inserida. Por outro lado, é na temática 
ambiental que a escola poderia apresentar um impacto significativo na sociedade, mediante a criação de canais de comunicação com a população que possibilitem a discussão e reflexão sobre o papel dos cidadãos quanto ao meio ambiente (AMORIM; AZEVEDO; COSSÍO, 2007, p.21).

Para EdaTassara (2001, p. 210), a participação e o ambientalismo são indissociáveis, "racionalmente, é impossível separar uma leitura da questão ambientalista [...] da ideia de incremento organizativo da participação das camadas cada vez mais amplas das humanidades que habitam o planeta".

Evidencia-se, também, que as práticas socioambientais educativas de caráter colaborativo têm se revelado como veículo importante na construção de uma nova cultura de diálogo e participação (ARNSTEIN, 2002 apud JACOBI; TRISTÃO; FRANCO, 2009, p.68).

Nessa direção, foi introduzido, em 2001, no Censo escolar, questões sobre a participação da comunidade em diversas atividades na escola:

Ele nada diz sobre a interação efetiva e real entre a escola e a comunidade em relação a certos temas e, além disso, não permite avaliar o verdadeiro impacto dessas atividades comunitárias desenvolvidas pela escola. No entanto, é um bom começo avaliar o grau em que as escolas que oferecem EA desenvolvem essas atividades (AMORIM; AZEVEDO; COSSÍO, 2007, p.23).

Um estudo foi realizado (VEIGA; AMORIM; COSSÍO,2005) objetivando analisar os dados dos censos escolares de 2001 (ano em que as questões relacionadas à EA foram introduzidas) a 2004. Entre os resultados está a construção inicial de indicadores. O índice de desenvolvimento da Educação Ambiental (IDEA) é composto por três dimensões e seus respectivos indicadores, conforme Quadro 1:

\begin{tabular}{|c|c|c|}
\hline Dimensão & Componentes / Indicadores & Detalhamento \\
\hline \multirow[t]{5}{*}{ Educação Ambiental } & \multirow[t]{2}{*}{ Acesso à EA } & $\begin{array}{llll}\begin{array}{l}\text { Cobertura } \\
\text { matrículas }\end{array} & \text { em } & \text { relação às } \\
\end{array}$ \\
\hline & & $\begin{array}{l}\text { Porcentagem de escolas que } \\
\text { oferecem EA }\end{array}$ \\
\hline & \multirow{3}{*}{$\begin{array}{l}\text { Índice de diversificação } \\
\text { modalidades das } \\
\text { (porcentagem de escolas que } \\
\text { oferecem três modalidades de } \\
\text { Educação Ambiental) }\end{array}$} & Projetos \\
\hline & & $\begin{array}{l}\text { Inserção da temática ambiental } \\
\text { nas disciplinas }\end{array}$ \\
\hline & & Disciplinas especiais \\
\hline \multirow[t]{2}{*}{ Apoio da escola à EA } & Equipamentos & $\begin{array}{l}\text { Videocassete, televisão, } \\
\text { computadores para uso } \\
\text { pedagógico e acesso à internet }\end{array}$ \\
\hline & Infraestrutura das escolas & $\begin{array}{l}\text { Videoteca, biblioteca, } \\
\text { laboratório de informática, sala } \\
\text { de tv e vídeo, banheiro fora da } \\
\text { escola, banheiro dentro da escola } \\
\text { e depósito de alimentos }\end{array}$ \\
\hline \multirow[t]{2}{*}{$\begin{array}{l}\text { Participação } \\
\text { comunitária }\end{array}$} & Participação em campanhas & $\begin{array}{l}\text { TV Escola, outros Programas da } \\
\text { TV Educativa }\end{array}$ \\
\hline & Ações comunitárias & $\begin{array}{l}\text { Comunidade colaborando na } \\
\text { manutenção de hortas, pomares e } \\
\text { jardins; mutirão de limpeza da } \\
\text { escola; mutirão de manutenção } \\
\text { da estrutura física da escola }\end{array}$ \\
\hline
\end{tabular}

Quadro 1 - Dimensões e Indicativos do IDEA

Fonte: elaborado pelos autores com base em Amorim, Azevedo e Cossío (2007, p. 26) 
O estudo indica que "as porcentagens de participações em qualquer uma das três dimensões estudadas são realmente baixas, e, além disso, é possível incrementar essa participação" (AMORIM; AZEVEDO; COSSÍO, 2007, p.23). A visão de participação apontada pelo censo relaciona-se as atividades braçais, como mutirões e manutenção de espaços, porém a participação nas questões políticas e pedagógicas da unidade não foi enunciada. O desafio da escola é aproximar-se da comunidade, valorizando todo o potencial comunitário, o que envolve outras dimensões para além dos trabalhos manuais.

Os próximos itens focam estratégias e propostas de EA em Fernando de Noronha partindo de um olhar de uma educação progressista materializada na Educação Ambiental.

\section{Caracterização e contextualização de Fernando de Noronha}

O Arquipélago de Fernando de Noronha tem seu descobrimento datado de 1503, na ocasião em que a embarcação liderada por Américo Vespúcio colidiu em uma das ilhas. A história do território perpassa por invasões e ocupações de diferentes grupos, como holandeses, franceses, americanos e italianos, que motivaram Portugal a tornar o Arquipélago um presídio comum.

Em 1938, a ilha foi entregue à União para a instalação de um presídio político rapidamente substituído pela criação do Território Federal de Fernando de Noronha, em 1942. O Arquipélago foi ocupado por militares, devido à entrada do Brasil na Segunda Guerra Mundial, o domínio militar vigorou por 45 anos. Com a transição de governo militar para civil, em 1987, nomeou-se o primeiro governador civil do Arquipélago e constituíram-se as unidades de conservação.

As diferentes ocupações e períodos de abandono de Noronha influenciaram a identidade de seus moradores, sendo que a "origem do núcleo fundador é dada aos funcionários do presídio (civis) e militares de baixo escalão que chegaram após a desativação do presídio" (ICMBio/MMA, 2005, p.209).

A pesquisadora Janirza Lima (2000, p. 34) classificou as relações sociais dos noronhenses em três tipos: impregnadas pelo imobilismo - reflete o período de abandono e do presídio; sustentadas pela transitoriedade - trata do caráter temporário das relações e habitantes; moldadas pela disciplina - reflete a submissão dos tempos dos militares e a vida regrada, disciplinada pela hierarquia e ordem imposta.

Essas relações sociais contribuem para a construção da identidade dos noronhenses, sendo que um indicador da existência da cultura local é a presença constante dos conceitos de ilhéu e haule nos discursos. Em termos gerais, ilhéus são aqueles nascidos na ilha e haules são os que chegaram de fora. A distinção tem relação direta com a vida cotidiana, pois orienta o acesso à terra (só ilhéu tem direito) e a permanência no Arquipélago, dentre outros (ICMBio/ MMA, 2005, p.205).

O Arquipélago de Fernando de Noronha tem $26 \mathrm{Km}^{2}$ e é formado por 21 ilhas, ilhotas ou rochedos (LINSKER, 2011, p. 14) distante $375 \mathrm{Km}$ de Natal e $575 \mathrm{Km}$ de Recife. A ilha principal, de mesmo nome do Arquipélago, é a única habitada com população estimada entre 2.630 habitantes (IBGE, 2010) e 4.000 habitantes (dados extraoficiais da administração do Distrito Estadual de $\mathrm{FN}^{6}$ ), distribuídos em uma área de $17 \mathrm{Km}^{2}$.

O Arquipélago é uma região geoeconômica, social e cultural instituído sob a forma de Distrito Estadual (Constituição Estadual de Pernambuco, 1989, artigo 96). A gestão do território é feita pelo Administrador Geral, indicado pelo governador de Pernambuco.

6 Dado de 2013 obtido em diálogo com funcionários do Setor de Migração da Administração do Distrito Estadual Fernando de Noronha. 
O espaço físico que tem gestão administrativa do Governo de Pernambuco, por meio da Administração do Distrito Estadual Fernando de Noronha (ADEFN), é a Área de Proteção Ambiental (APA) de Fernando de Noronha - Rocas - São Pedro e São Paulo. O território da APA é cogestionado pelos administradores da ADEFN e da APA. A APA foi criada em 1986 (Decreto Federal $n^{\circ}$ 92.755) e compreende a porção urbana da Ilha, bem como áreas destinadas à conservação dos recursos naturais e da vida silvestre, cerca de $50 \%$ da ilha.

$\mathrm{O}$ restante da Ilha principal e todas as demais ilhas e rochedos foram declaradas Parque Nacional Marinho de Fernando de Noronha (Parnamar) em 1988 (Decreto Federal $\mathbf{n}^{\circ}$ 96.693) com área total de $112,7 \mathrm{~km}^{2}$. Sua gestão é feita pelo Instituto Chico Mendes de Biodiversidade e Conservação (ICMBio).

Para além desses órgãos, contribuem com a gestão do Distrito de Fernando de Noronha, de forma consultiva, os Conselhos - APA, Parnamar, Turismo, Assistência Social, Saúde e Educação (Coned), e a Assembleia Popular Noronhense. Somam-se a eles o Conselho Distrital de caráter fiscalizador da ADEFN.

A principal atividade econômica da ilha é o turismo. Porém, de acordo com o Plano de Manejo da APA, ainda há prática de agricultura e pecuária na região (ICMBio/MMA, 2005, p.211). No entanto, por apresentar produção de alimentos incipiente, a maior parte do consumo dos moradores da Ilha depende do transporte de barcos e aviões vindos do continente.

A pegada ecológica da Ilha é 135 vezes o tamanho do Arquipélago, 14\% maior que a média mundial (ICMBio/MMA, 2008, p.7), o que pode ser explicado por sua infraestrutura: dessalinização de água do mar para abastecimento urbano, geração de energia por termoelétrica a base de óleo diesel, rede de coleta de esgoto que não atende toda a Ilha, resíduos sólidos encaminhados ao continente e transporte diário de turistas via avião, que permanecem, em média, três dias em Fernando de Noronha.

Com relação à Educação Básica, o Arquipélago conta com duas unidades escolares. O Centro Integrado de Educação Infantil Bem-me-Quer e a Escola de Referência em Ensino Médio Arquipélago Fernando de Noronha (EREM AFN). A EREM AFN tem ensino fundamental, médio e educação de jovens e adultos, atendendo aproximadamente 495 estudantes; tem uma localização central no território, conta com a única quadra coberta do Arquipélago e um auditório utilizado por toda a população. Dessa forma, é possível afirmar que ela desempenha um papel de centro cultural na Ilha.

Sendo a Educação Ambiental foco da presente pesquisa ressalta-se seu potencial na formação dos habitantes do Arquipélago para eles contribuírem na conservação da biodiversidade local e na educação dos visitantes.

\section{Metodologia}

A metodologia da pesquisa é de natureza qualitativa. Lüdke e André (1986) apontam que essa abordagem na área de educação caracteriza-se por um contato direto do pesquisador com a realidade e, desse modo, oferece a possibilidade de documentar o não documentável.

Dentre as pesquisas de natureza qualitativa, a presente investigação dialoga com a pesquisa-intervenção e a etnografia. A aproximação com a pesquisa-intervenção ocorre na medida em que parte do trabalho foi realizado por meio de ações na realidade local:

A pesquisa-intervenção consiste em uma tendência das pesquisas participativas que busca investigar a vida de coletividades na sua diversidade qualitativa, assumindo uma intervenção de caráter socioanalítico (ROCHA, 2003, p.66). 
No trabalho, interviu-se na realidade de indivíduos e instituições de Fernando de Noronha através de formações com estudantes, gestores e supervisores escolares e a comunidade em geral, durante o ano de 2013.

Por fim, aproxima-se da pesquisa etnográfica pela imersão realizada na comunidade com o objetivo de conhecê-la em profundidade. Buscou-se compreender a realidade local em sua complexidade e registrar no diário de campo tudo que fosse possível, para, posteriormente, selecionar os dados relacionados com o objeto do estudo específico. Para Marli André (2012) a etnografia, no seu sentido mais amplo, pode ser definida como um processo sistemático de observar, detalhar, descrever, documentar e analisar o estilo de vida de uma cultura para apreender seu modo de viver em seu ambiente natural.

Para a coleta de dados foram utilizadas análise de documentos, observação participante e intervenção educadora ambientalista.

\subsection{Análise de documentos de Fernando de Noronha}

A técnica de "análise documental busca identificar informações factuais nos documentos a partir de questões e hipóteses de interesse" (CAULLEY, 1981 apud LUDKE; ANDRÉ, 1986, p. 38). Na presente pesquisa, foi utilizada para identificar de que forma a EA está presente nos documentos e se a participação é citada e proposta. A seleção dos documentos foi feita mediante a leitura de referenciais legais do DEFN que regulamentam procedimentos e ações no território.

\subsection{Observação participante}

As técnicas de observação participante, de acordo com Valles (1997), são aquelas em que o investigador presencia diretamente o fenômeno que estuda, não se atendo apenas às informações indiretas fornecidas por entrevistas ou documentos. Com o objetivo de buscar realismo e construção de significado, o investigador conta com o ponto de vista dos sujeitos estudados (OLABUÉNAGA; ISPIZUA, 1989 apud VALLES, 1997).

A observação participante foi selecionada para aproximar a pesquisadora do território e dos sujeitos da pesquisa, reconhecer o modo de viver, as relações estabelecidas entre os indivíduos, consolidar uma relação de respeito, apresentar a proposta de estudo aos grupos envolvidos e, especificamente, identificar e obter informações sobre as atividades de Educação Ambiental que ocorreram em Fernando de Noronha no ano de 2013.

Esta foi desenvolvida durante reuniões do Conselho Escolar e reuniões de pais da EREM AFN, reuniões dos Conselhos de Educação, Saúde, APA e Parnamar, Conferência Distrital de Meio Ambiente, Fórum Distrital de Educação, audiências públicas e eventos relacionados ao meio ambiente, entre outros encontros e ações informais que ocorreram no cotidiano da pesquisadora durante a estadia no Arquipélago.

Os dados da observação participante foram coletados por meio de um caderno composto por anotações de campo, que é "o relato escrito daquilo que o investigador ouve, vê, experiência e pensa no decurso da coleta e refletindo sobre os dados de um estudo qualitativo" (BOGDAN; BIKLEN, 1994, p. 150).

\subsection{Intervenção educadora ambientalista}

Os projetos de EA desenvolvidos durante os trabalhos de campo da pesquisadora estão nomeados, neste artigo, como intervenção educadora ambientalista.

A intervenção educacional pode ser concretizada em intervenções na realidade socioambiental local, através de projetos pedagógicos em uma perspectiva freireana. 
Neste sentido, o projeto é uma oportunidade de se criar um movimento no cotidiano de inserção crítica dos atores. O projeto é um desafio que se coloca para, ao entender a realidade, procurarmos enfrentar os problemas transformando a realidade e a nós, reciprocamente (GUIMARÃES, 2005, p. 196).

O caráter ambientalista das intervenções realizadas está relacionado à utopia de contribuir com a transição de Fernando de Noronha para uma sociedade mais sustentável, tendo como princípios cinco conceitos: comunidade, diálogo, identidade, potência de ação e felicidade (ALVES et al. 2010).

Foram promovidos processos educadores ambientalistas por meio do Projeto Noronha Além Mar na EREM AFN, reuniões da Comissão de Meio Ambiente e Qualidade de Vida (Com-vida), durante o ano de 2013 e em julho de 2014, e do Projeto Férias Ecológicas, em janeiro de 2014.

Os dados foram documentados no caderno de campo e em relatórios sobre cada uma das atividades.

\section{Um olhar para os documentos oficiais do Arquipélago}

Alguns documentos relevantes para a organização do território não apresentam referência aos temas em foco, são eles: Lei Orgânica do DEFN; Estatuto do Coned e Projeto Político Pedagógico da EREM AFN.

Os documentos que recomendam, regulamentam e institucionalizam a EA em Fernando de Noronha são: os planos de manejo da APA e do Parnamar; o Noronha + 20; e as orientações pedagógicas para a inserção da EA para o ensino básico de Pernambuco.

De forma geral, todos os documentos supracitados estão em sintonia com a PNEA e o ProNEA por meio de uma visão holística e sistêmica da EA relacionada às questões locais.

O Programa Noronha +20 foi construído em parceria entre ICMBio e ADEFN. O documento foi elaborado de maneira participativa com proposição de ações para diversos públicos do território, busca articulação das instituições e foca no desenvolvimento da autonomia e da participação dos ilhéus. No entanto, a concretização das ações constitui um desafio, já que as instituições, muitas vezes, não se dispõem a assumir mais encargos, ocupadas com o cumprimento de outras políticas já instituídas. A institucionalização do Noronha +20 torna-se essencial para fomentar sua aplicação no cotidiano e capilaridade.

As orientações pedagógicas foram construídas pela Secretaria de Educação de Pernambuco com o "objetivo de subsidiar o trabalho pedagógico do professor no desenvolvimento de temas e atividades transversais e interdisciplinares, de caráter socioambiental" (PERNAMBUCO, 2013, p. 7). Há um caderno específico para o trabalho de EA que subsidia a disciplina obrigatória da EREM AFN ministrada para o ensino fundamental I e Médio. A existência da disciplina de EA vai na contra mão da PNEA $(9795 / 1999)$ que aponta que a EA deva ser desenvolvida de forma "integrada, contínua e permanente em todos os níveis e modalidades do ensino formal" (BRASIL, 1999, artigo 10), ou seja, a educação ambiental não deve ser implantada como disciplina específica no currículo de ensino.

As Diretrizes Curriculares Nacionais de Educação Ambiental (BRASIL, 2012) reforçam a não disciplinarização da EA em seu artigo oitavo. Para auxiliar a introdução da EA de forma integrada, o meio ambiente já era indicado como tema transversal pelos Parâmetros Curriculares Nacionais (BRASIL,1997) ${ }^{7}$. Temas transversais envolvem "diferentes segmentos

\footnotetext{
${ }^{7}$ Em 2017, o MEC lançou a Base Nacional Comum Curricular, na área da educação ambiental representou um retrocesso desconstruindo parte dos avanços já presentes nos PCN e nas DCN de EA. Na BNCC a educação ambiental está ausente. Um tema transversal chamado Meio Ambiente foi incluído de forma bastante tímida.
} 
da sociedade e que levantam problemas cuja reflexão nos leva para além de um único campo do conhecimento" (OLIVEIRA, 2007, p.107). Por esse motivo, a transversalidade exige que os temas trabalhem teorias de diferentes disciplinas e campos do saber. Assim, existe um relativo consenso na literatura e entre militantes e acadêmicos ligados à área de que a Educação Ambiental não deva ser limitada a uma disciplina (OLIVEIRA, 2007, p.104).

Soma-se a isso a suposição de que "havendo um profissional na escola dedicado ao assunto, os outros professores não se envolveriam com a questão" (OLIVEIRA, 2007,p.105). Dados obtidos na observação participante convergem com a consideração supracitada, como por exemplo, o questionamento de um professor em uma reunião de formação "por que temos que realizar os planos de aula [de EA] com os estudantes se já temos o educador ambiental? (CADERNO DE CAMPO, 2013, s/p).

O Plano de Manejo do Parnamar, datado de 1990, apresenta um subprograma de interpretação ambiental e outro de Educação Ambiental, porém os conceitos não são definidos e/ou diferenciados no documento. O de interpretação foca na construção de trilhas, recursos didáticos e infraestrutura que possibilite a interpretação ambiental pelos visitantes. Já o subprograma de EA tem a comunidade, escola e visitantes como sujeitos da atuação. Como objetivos destacam-se a "conscientização" e "desenvolver e incrementar o processo de participação comunitária na proteção e na preservação do parque" (ICMBio, 1990, p.160). O plano aponta algumas estratégias para atingir os objetivos, entre elas eventos na comunidade, articulação com a escola e visitas ao Parque, porém, a maior parte delas com o objetivo de informar. Não foi possível identificar de que forma a participação comunitária seria incentivada.

Por fim, o Plano de Manejo da APA ressalta a importância da EA, apresenta um diagnóstico das ações locais, propostas de concepção de Educação Ambiental desejada para o Arquipélago e sugere a necessidade de um programa de EA para Ilha. Ressalta-se que o Plano de Manejo da APA foi publicado em 2005 e, até a presente data, não há um programa de EA no Arquipélago nem diálogos públicos sobre a sua construção.

O olhar para os documentos oficiais permite considerar a necessidade de institucionalizar políticas públicas de EA no Arquipélago para fomentar sua aplicação no cotidiano e a capilaridade no território. Porém, os Planos de Manejo da APA e do Parnamar e de outras áreas estudadas demonstram que não basta a institucionalização formal (entendidas, aqui, como normas legais e estruturas administrativas), sendo de fundamental importância a ambientalização e o enraizamento da EA nas instituições.

Destacam-se, aqui, duas pesquisas relacionadas às políticas públicas que afirmam a necessidade de outros instrumentos para além da institucionalização. Ísis Akemi Morimoto (2014) aponta a importância de efetivar políticas públicas voltadas à ampliação e qualificação da participação em processos decisórios, e a indispensabilidade de apropriação, pelos cidadãos, de mecanismos voltados ao controle social e ao melhor acesso à justiça. Semíramis Biasoli (2015) defende a relevância da dimensão da política do cotidiano, considerando as motivações subjetivas dos atores sociais e as forças instituintes na formulação e implantação de políticas públicas.

Partindo da premissa da distância existente entre os documentos e a prática cotidiana e a presença de experiências significativas que ocorrem sem apoio legal em Fernando de Noronha, os autores do presente artigo optaram por mapear as atividades de Educação Ambiental desenvolvidas na Ilha no ano de 2013, buscando sua relação com a participação.

\section{Mapeamento das atividades de Educação Ambiental de Fernando de Noronha}

O mapeamento das atividades de Educação Ambiental realizadas no Distrito de Fernando de Noronha, entre março de 2013 e janeiro de 2014, foi feito com quatro objetivos 
centrais: identificar atores e instituições propositoras; responsáveis pelas ações, projetos e/ou programas; público envolvido; relação com a participação.

Os dados foram coletados por meio de observação participante e por e-mail. As observações participantes foram realizadas durante o ano de 2013 e registradas em diário de campo. Os proponentes foram contatados, posteriormente, para outras informações. Ressaltase que as atividades de EA mapeadas foram aquelas que as instituições responsáveis consideram ser de EA, ou seja, não necessariamente alinhadas com a proposta enunciada neste trabalho.

Foram identificadas 29 atividades desenvolvidas por nove instituições, sendo cinco públicas (ADEFN, Secretaria de Meio Ambiente e Desenvolvimento Sustentável de Pernambuco - Semas, ICMBio, duas unidades escolares), duas organizações não governamentais, um coletivo e uma empresa privada.

Dentre as instituições, nenhuma tem missão ligada exclusivamente à EA, ou seja, não têm nela a sua razão de existir. Porém, a Semas, as ONGs e o coletivo apresentam na missão e/ou nos objetivos o compromisso com desenvolvimento da Educação Ambiental, o que indica uma preocupação com a temática. Somam-se a isso obrigações legais de realizar atividades de EA do Parnamar e da APA (Sistema Nacional de Unidades de Conservação fortalecido pelas Estratégias Nacionais de Comunicação e Educação Ambiental em Unidades de Conservação) e das duas unidades escolares (Lei de Diretrizes e Bases da Educação, PNEA e DCN de EA).

A missão e objetivos institucionais influenciam, entre outros, na definição do responsável e executor das ações desenvolvidas. A maior parte das instituições tem um educador ambiental ou coordenador com outras atribuições (ICMBio, ADEFN, Centro de Educação Infantil, ONG, Coletivo). Apenas três das instituições tem um educador ambiental focado nas atividades educativas (EREM AFN, uma ONG e empresa privada). A EA sendo responsabilidade de um indivíduo com outras atribuições institucionais pode prejudicar a criação e implementação de propostas estruturantes, continuadas e permanentes, devido, principalmente, a dois fatores: à diversificação de ações, apontando outras prioridades para as instituições e/ou para os supervisores hierárquicos, e a formação dos técnicos e responsáveis pela EA não ligada à temática.

Como exemplo, tem-se duas situações. As ações do ICMBio são desenvolvidas por um fiscal, que tem um reconhecimento positivo no território por sua atuação com EA, e por voluntários do Parnamar que ficam três meses na ilha. Não há um programa institucional que articule as atividades desenvolvidas pelo fiscal com a atuação dos voluntários. As atribuições como fiscal (cargo ao qual está relacionada sua contratação) dificultam que ele fortaleça as ações do voluntariado. Dessa forma, os voluntários com pouco tempo para se inteirar e integrar no Arquipélago têm dificuldades de atuar, o que resulta numa fragilidade do ICMBio para desenvolver ações de EA estruturantes e permanentes. No caso da ADEFN foi possível identificar uma atuação tímida no ano de 2013, com a realização da II Conferência Distrital de Meio Ambiente (CADERNO DE CAMPO, 2013).

Com relação ao público envolvido nas atividades, a maior parte tem moradores (sete ações), estudantes (seis) da EREM AFN e os turistas (seis). Veja-se a Figura 1. 


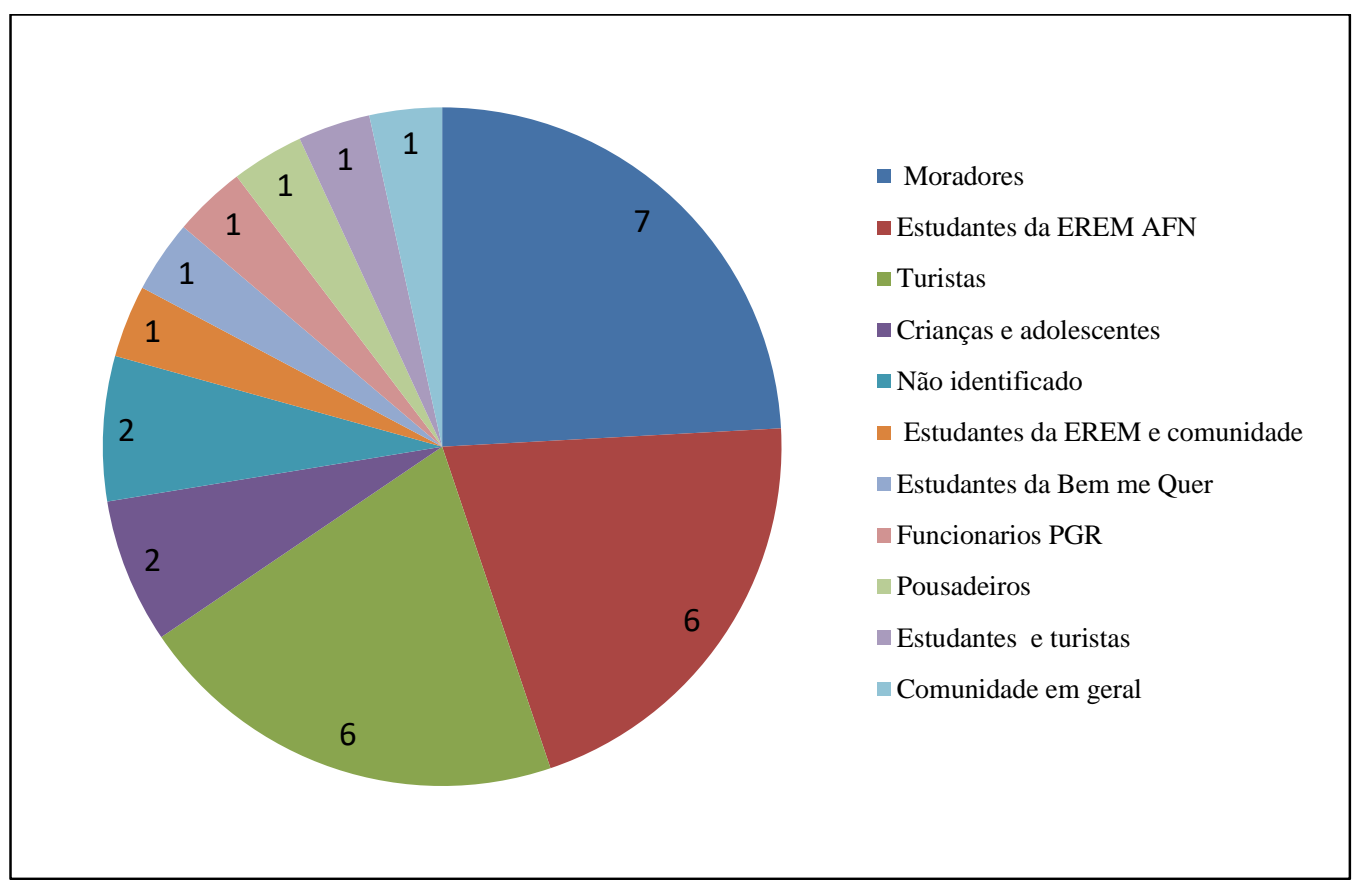

Figura 1 - Público das ações de Educação Ambiental Fonte: elaborado pelos autores

Os estudantes da EREM AFN são sujeitos de dez das 29 ações, sendo que em seis são o público exclusivo. Apesar de trabalhar com o mesmo público, a realização de parcerias não é frequente no Arquipélago, apenas duas ações são desenvolvidas por duas instituições em conjunto. Dessa forma, a sobreposição de temas é recorrente. Numa reunião um propositor de ações de EA afirmou, e outro concordou, que "para fazer ações conjuntas é essencial ter a clareza do que a sua instituição ganhará com isso" (CADERNO DE CAMPO, 2013, s/p). A fala pode demonstrar uma visão individualista e fragmentada e gera questionamentos sobre as motivações de desenvolver ações: ligadas ao público envolvido ou com foco na promoção institucional. A prioridade das ações educadoras não deveria ser os envolvidos no processo e os ganhos para todo o território?

Com relação a atuação com outros públicos, para além dos estudantes, as ações são limitadas pelo caráter majoritariamente transitório dos moradores da Ilha, o que dificulta uma proposta continuada. Um dos propositores de EA afirmou, em conversas com a pesquisadora, sua baixa motivação em oferecer atividade formativa com o público adulto, devido ao baixo potencial de desdobramentos no território dada a transitoriedade dos ilhéus, principalmente, os trabalhadores da área de turismo e prestação de serviços (CADERNO DE CAMPO, 2013).

\section{Técnicas utilizadas para trabalhar a participação na Educação Ambiental}

Os resultados apresentados nesta seção referem-se às ferramentas utilizadas para desenvolver a participação em atividades de EA em Noronha, no ano de 2013. Foram categorizados em níveis de participação, tendo como referência as pesquisas de DíazBordenave (1994), que as classifica em informativo, consultivo, corresponsável, assessorado, autogestionado. A seleção dessa classificação é para auxiliar a organização das técnicas de forma didática e proporcionar uma visão geral da inserção da participação nas atividades de EA. Aspectos relacionados ao caráter subjetivo da participação não serão contemplados por 
meio dessa categorização, pois o modo como os dados foram coletados dificultam um olhar nessa perspectiva ${ }^{8}$.

A maior parte das atividades mapeadas tem um caráter informativo, com uso de diferentes ferramentas. $O$ acesso às informações é uma das bases para a construção de conhecimentos, enriquecimento dos argumentos, resolução de problemas e identidade com temas, situações, espaços e indivíduos. O modo como a informação é disponibilizada influencia no caráter participativo. No presente estudo, a disseminação de informação se deu por encontros presenciais, vivências no território, produção de jornal virtual, página na internet, vídeos e spots de rádio. O conteúdo das informações pode contribuir para a aproximação dos indivíduos com o território. Todas as informações disponibilizadas nos materiais identificados têm relação com Fernando de Noronha.

Algumas atividades promovem, para além do caráter informativo, uma consulta à comunidade buscando identificar informações, conhecimentos e desejos de um grupo. As técnicas utilizadas são: diálogos para levantar conhecimentos prévios; entrevistas; trabalhos em grupo para identificar, propor e apresentar soluções para questões ambientais locais; construção de acordos de convivência; questionário, roda de diálogos e produção de desenhos para identificar preferências de técnicas, temáticas e relação com as atividades.

Quando as pessoas são consultadas, pode ocorrer um processo de aprendizagem relacionado à reflexão, organização de ideias, construção de conhecimentos significativos para a vida de cada um. Porém, é importante o esclarecimento do caráter da consulta (educativo, consultivo, deliberativo) e possibilidades de desdobramentos. A ausência de esclarecimento pode exercer influência negativa nos indivíduos, que ficam desmotivados a participar de atividades e espaços. Por exemplo, na II Conferência Distrital de Meio Ambiente teve um grupo de trabalho de EA que dialogou e propôs caminhos para a EA na Ilha. Porém, não existiam estratégias claras da ADEFN sobre a forma como as deliberações da Conferência são, ou não, implementadas e não houve nenhuma ação da Administração, que veio a público, sobre os encaminhamentos dados às proposições.

Algumas técnicas, dinâmicas e espaços podem estimular a participação por meio do fomento a uma responsabilidade conjunta, a corresponsabilidade dos indivíduos. As técnicas presentes nas atividades de EA de FN são: sala de aula em formato de roda, manutenção do espaço de convivência coletivo, construção conjunta de Projeto de EA e de planos de aula, criação de spots de rádio, produção de material de divulgação, construção de acordos coletivos (local de encontro, ações e parceiros), atividades práticas e saídas a campo. Soma-se a isso o desejo de construir o conhecimento de forma coletiva, conforme expressam os objetivos de algumas das atividades.

Para ilustrar, destaca-se a construção entre ONG e escola de um projeto de Educação Ambiental que foi realizado na unidade escolar. A construção ocorreu por meio de oficinas participativas das quais participaram funcionários da $\mathrm{ONG}$, coordenadores e professores da escola. Dessa forma, o projeto não era da ONG na escola e, sim, um projeto das duas instituições, o que fortaleceu a iniciativa ao ampliar o envolvimento com o planejamento e a ação.

Atividades com foco numa participação assessorada e autogestionada foram incipientes, um caso em cada uma delas.

O caráter assessorado está relacionado ao apoio de um técnico a um grupo para realização de ações, projetos ou programas por meio da realização de reuniões. Em Noronha, foi ofertado um curso de Sustentabilidade para os meios de hospedagem da Ilha. Numa segunda fase, algumas pousadas foram selecionadas para ter um acompanhamento da auditora

${ }^{8}$ Complementou-se o caráter subjetivo da participação por meio da realização de entrevistas em etapa posterior da pesquisa. 
ambiental da ONG, visando implantar ferramentas de diminuição de impactos ambientais aprendidas no curso 9 . No caso, os indivíduos já tinham autonomia para desenvolver suas ações, sendo apenas acompanhados pela profissional. De acordo com a auditora, o acompanhamento mostrou-se importante para a transição dos estabelecimentos. Esse exemplo evidencia o papel mobilizador e incentivador que uma assessoria pode oferecer.

Por fim, apenas uma instituição trabalha com a autogestão, sendo que todos os membros cuidavam de todas as ações desenvolvidas. Segundo Baremblit (2002, p. 17):

Esse processo de autoanálise das comunidades é simultâneo ao processo de autoorganização, em que a comunidade se articula, se institucionaliza, se organiza para construir dispositivos necessários para produzir, ela mesma, ou para conseguir recursos de que precisa para a manutenção e melhoramento de sua vida na Terra.

A autogestão depende do amadurecimento do grupo e é um desafio constante. No Coletivo Circo Caracas todos os membros são responsáveis pela gestão, sendo as decisões tomadas em reuniões caracterizadas pela participação, diálogo e horizontalidade.

A diversidade de ferramentas identificadas que envolvem a participação ilustra algumas possibilidades de trabalhar com a temática em atividades de EA. Porém, as técnicas se associam a uma filosofia por trás da prática, assim, a participação pode ter tanto um caráter emancipatório quanto de legitimação do instituído (DEMO, 1996).

De acordo com Demo a "participação, por conseguinte, não é ausência, superação, eliminação do poder, mas outra forma de poder" (DEMO, 1996,p. 20), logo a participação emancipatória tende a criar conflitos visto que a luta por poder requer que alguém divida ou perca poder e a maior parte dos indivíduos não está disposta a abrir mão dele. Desse ponto de vista, Demo (1996, p. 138) evidencia que "o governo aprecia participação como estratégia de legitimação, não como instrumento de divisão de poder".

Realça-se assim a necessidade de um olhar mais atento para a filosofia que fundamenta ações, projetos e programas, pois por mais que as técnicas sejam progressistas sua filosofia pode ser autoritária, hierárquica e/ou preconceituosa.

Por fim, observou-se o uso de diferentes ferramentas participativas nas 29 atividades de EA mapeadas em Noronha, porém com um baixo potencial de formação de sujeitos participativos devido, principalmente, ao seu foco na informação, a não enunciação da participação enquanto objetivo das atividades e a não continuidade no tempo e no espaço das ações. Dessa forma, o conjunto de atividades de EA no Arquipélago tem contribuído de uma forma tímida para a formação de sujeitos participativos que possam auxiliar a transição para uma sociedade mais sustentável. Um caminho possível é a interiorização da participação enquanto processo, enquanto metodologia que oriente a EA no território.

\section{Considerações finais}

Refletir sobre EA e a participação em Fernando de Noronha remete a um olhar sobre o perfil de seus moradores, que são reflexo de sua história. A Ilha vivenciou momentos de abandono, presídio correcional e político, governo militar; atualmente, é o único Distrito Estadual do país, com um administrador nomeado e não eleito. Apresenta a peculiaridade de ser constituído por duas unidades de conservação e tem conselhos para sua gestão. A transitoriedade dos moradores e a história do Arquipélago podem ter contribuído para a formação de sujeitos passivos às decisões no território, porém como escreve Demo (1996) a participação é conquista e a situação de opressão é o ponto de partida para a luta participativa.

Trata-se de um processo histórico infindável, que faz da participação um processo de conquista de si mesma. Não existe participação suficiente ou acabada. Não existe

\footnotetext{
${ }^{9}$ Maiores informações sobre esse trabalho em: OLIVEIRA (2015).
} 
como dádiva ou como espaço preexistente. Existe somente na medida de sua própria conquista (DEMO, 1996,p.12-13).

A EA apresenta uma relação indissociável com a participação (TASSARA, 2001) com grande potencial para contribuir com transformações socioambientais locais. Identificou-se, no presente estudo, que a maior parte das atividades de EA desenvolvidas em 2013 teve os estudantes como público. Sugere-se que se as instituições desejam contribuir para a transição de Noronha em direção a um território mais sustentável é importante a valorização e diferenciação dos públicos de atuação. $\mathrm{E}$, dessa forma, enfrentar o desafio de formação de sujeitos ainda que transitórios no território.

Soma-se a isso a constatação de que no Arquipélago não há espaços de participação instituídos de jovens, os quais também não participam do conselho escolar, dos conselhos da Ilha ou da associação noronhense. Esses elementos são indícios de que as atividades de EA pouco tem estimulado a participação dos estudantes.

Na verdade, educação que não leva à participação já nisto é deseducação, porque consagra estruturas impositivas e imperialistas, transformando o educador manipulador em figura central do fenômeno, em vez de elevar o educando a centro de referência (DEMO, 1996, p.53).

O desafio para as nove instituições do Arquipélago que desenvolvem EA é realizar uma análise crítica das atividades desenvolvidas, focada principalmente em seus objetivos e motivações. A existência de educadores ambientais com diferentes perfis na Ilha pode contribuir com a EA do território por meio da promoção de encontros formativos entre eles, que promovam o diálogo e trocas significativas. Porém, existe o desafio de mobilização que é uma arte: "Com isto se sugere que não se pode inventar um manual de instruções, como se fosse algo mecânico e operacionalizável” (DEMO, 1996, p. 130) e, sim, que se aproveite a possibilidade de experimentar reflexivamente.

A realização de processos participativos fomentados pelas ações, projetos e programas de EA no Arquipélago pode contribuir para o desenvolvimento de sujeitos que se comprometem com seu território e com a cidadania planetária, desde que tenham como pano de fundo a perspectiva emancipatória e uma educação progressista. A EA pode contribuir com a emergência e fortalecimento de sujeitos comprometidos com a construção de um mundo novo, seja ele materializado em Fernando de Noronha ou no planeta como um todo.

\section{Referências}

ALVES, D.M.G. et al. Em busca da sustentabilidade educadora ambientalista. Ambientalmente sustentable, Oleiros - Espanha, v.1, n. 9-10, p. 7-34, 2010.

AMORIM, É. P.;AZEVEDO, L.;COSSÍO, M. B. Aspectos preliminares. In: TRAJBER, R.;MENDONÇA, P. R. (Orgs.). Educação na diversidade: o que fazem as escolas que dizem que fazem educação ambiental. Brasília: Secretaria de Educação Continuada, Alfabetização e Diversidade, 2007. p. 21-35. (Coleção Educação para Todos, Série Avaliação, n. 6, v. 23).

ANDRADE, D. F. de et al.Da pedagogia à política e da política à pedagogia: uma abordagem sobre a construção de políticas públicas em educação ambiental no Brasil. Ciênc. educ., Bauru, v. 20, n. 4, p. 817-832, Out./Dez. 2014 . Disponível em:<http://www.scielo.br/scielo.php?script=sci_arttext\&pid=S151673132014000400004\&lng=en\&nrm=iso>. Acesso em: 11 ago. 2020.

ANDRÉ, M. E. D.A. de. Etnografia da prática escolar. 18 ed. Campinas: Papirus, 2012. 
ANTUNES, A. Escola, comunidade e família no município que educa. In: PADILHA, R. P.; MAIA, S. (Orgs.). Município que Educa: inovações em processo. São Paulo: Instituto Paulo Freire, 2011. p. 47-52.

BAREMBLIT, G. Compêndio de análise institucional e outras correntes. Teoria e prática. 5ed. Belo Horizonte: Instituto Félix Guatarri, 2002.

BIASOLI, S. A. Institucionalização de políticas públicas de educação ambiental: subsídios para a defesa de uma política do cotidiano.2015. 235p. Tese (Doutorado em Ciência Ambiental) - Escola Superior de Agricultura Luiz de Queiroz, Piracicaba, 2015.

BOGDAN, R.C.; BIKLEN, S.K. Investigação qualitativa em educação: uma introdução à teoria e aos métodos. Coimbra/Lisboa: Porto, 1994.

BRASIL. Decreto n. 92.755, de5 de junho de 1986. Declara Área de Proteção Ambiental o Território Federal de Fernando de Noronha, o Atol das Rocas e os Penedos de São Pedro e São Paulo, e dá outras providências. Brasília: Casa Civil, 1986.Disponível em:

<http://www.planalto.gov.br/ccivil_03/decreto/1980-1989/1985-1987/D92755.htm>. Acesso em: 11 ago. 2020.

BRASIL. Decreto $n$. 96.693, de 14 de setembro de 1988. Cria o Parque Nacional Marinho de Fernando de Noronha e dá outras providências. Brasília: Casa Civil, 1988. Disponível em: <http://www.planalto.gov.br/ccivil_03/decreto/1980-

1989/D96693.htm\#: :text=DECRETO\%20No\%2096.693\%2C\%20DE,o\%20que\%20disp\%C3\%B5e\% 20o\%20art>. Acesso em: 11 ago. 2020.

BRASIL. Constituição da República Federativa do Brasil. São Paulo: Imprensa Oficial do Estado, 1988.

BRASIL.Ministério da Educação. Lei n.9.394, de 20 de dezembro de 1996.Estabelece as Diretrizes e Bases da Educação Nacional. Brasília: MEC/SEF, 1996.Disponível em:

<http://portal.mec.gov.br/seesp/arquivos/pdf/lei9394_ldbn1.pdf>. Acesso em: 11 ago. 2020.

BRASIL. Secretaria de Educação Fundamental. Parâmetros curriculares nacionais: introdução aos parâmetros curriculares nacionais / Secretaria de Educação Fundamental. Brasília: MEC/SEF, 1997.

BRASIL. Lei n. 9.795, de 27 de abril de 1999. Dispõe sobre a educação ambiental, institui a Política Nacional de Educação Ambiental e dá outras providências. Brasília: Casa Civil, 1999. Disponível em:<http://www.planalto.gov.br/ccivil_03/leis/19795.htm>. Acesso em: 11 ago. 2020.

BRASIL. Ministério do Meio Ambiente. Departamento de Educação Ambiental; Ministério da Educação, Coordenação Geral da Educação Ambiental. Programa Nacional de Educação Ambiental.3. ed. Brasília: MMA, 2005. Disponível em: <https://www.mma.gov.br/estruturas/educamb/_arquivos/pronea3.pdf>. Acesso em: 13 ago. 2020.

BRASIL. Conselho Nacional de Educação. Resolução $n^{\circ}$ 2, de 15 de junho de 2012. Estabelece as Diretrizes Curriculares Nacionais para a Educação Ambiental. Brasília: MEC/CNE, 2012. Disponível em: <http://portal.mec.gov.br/dmdocuments/rcp002_12.pdf>. Acesso em: 11 ago. 2020.

BRASIL. Ministério do Meio Ambiente. Departamento de Educação Ambiental; Ministério da Educação, Coordenação Geral da Educação Ambiental. Programa Nacional de Educação Ambiental.4. ed. Brasília: MMA, 2014. 
CABRAL, A. A construção da escola democrática. Uma reflexão com base em Jacques Delors et al., Licínio Lima e Jaume Carbonell Sebarroja. Rev. Lusófona de Educação,Lisboa, s/v, n. 9, p. 181185,2007. Disponível em:<http://www.scielo.mec.pt/scielo.php?script=sci_arttext\&pid=S1645$72502007000100012 \& \operatorname{lng}=$ pt\&nrm=iso>. Acesso em: 11 ago. 2020.

CONFERÊNCIA Mundial Educação para Todos. Declaração Mundial de Educação para Todos. Plano de Ação para Satisfazer as Necessidades Básicas de Aprendizagem. Brasília: UNIFEC, 1990.

DEMO, P.Participação é conquista: noções de política social participativa. 3 ed. São Paulo: Cortez, 1996.

DÍAZ-BORDENAVE, J. E. O que é participação. 8 ed. São Paulo: Brasiliense, 1994.

FAUNDEZ, A.O Poder da participação. São Paulo: Cortez, 1993.

FREIRE, P. Pedagogia do Oprimido. Rio de Janeiro: Paz e Terra, 1981.

FREIRE, P. Pedagogia da autonomia: saberes necessários à prática educativa. 15 ed. São Paulo: Paz e Terra, 2000.

GADOTTI, M. Pátria educadora. Abrangência da proposta apresentada pela Presidenta Dilma Rousseff no discurso de posse... e algumas ideias a mais. São Paulo: Instituto Paulo Freire,2015. Disponível em: <https://www.paulofreire.org/images/pdfs/Patria_Educadora-Gadotti-290915.pdf>. Acesso em: 11 ago. 2020.

GHANEM, E. Educação e participação no Brasil: um retrato aproximativo de trabalhos entre 1995 e 2003. Educ. Pesqui., São Paulo , v. 30, n. 1, p. 161-188, Apr. 2004 . Disponível em: http://www.scielo.br/scielo.php?script=sci_arttext\&pid=S1517-

97022004000100009\&lng=en\&nrm=iso>. Acesso em: 11 ago. 2020.

GUIMARÃES, M. Intervenção educacional. In: FERRAROJR., L. A. (Org.) Encontros e Caminhos: formação de educadoras(ES) ambientais e coletivos educadores. Brasília: MMA, 2005.Vol. 1.

INSTITUTO BRASILEIRO DE GEOGRAFIA E ESTATÍSTICA - IBGE. Cidades. Brasília: IBGE, 2010.

Disponível em: $<$ http://www.ibge.gov.br/cidadesat/xtras/perfil.php?codmun=260545\&search=pernambuco|fernand o-de-noronha>. Acesso em: 11 ago. 2020.

INSTITUTO BRASILEIRO DO MEIO AMBIENTE E DOS RECURSOS RENOVÁVEIS (IBAMA) e FUNDAÇÃO PRÓ-NATUREZA (Funatura). Plano de Manejo do Parque Nacional Marinho de Fernando de Noronha.Brasília: IBAMA/FUNATURA,1990. Disponível em: $<$ https://www.icmbio.gov.br/portal/images/stories/biodiversidade/_PARNA_MARINHA_DE_FERNA NDO_DE_NORONHA.pdf>. Acesso em: 11 ago. 2020.

INSTITUTO CHICO MENDES DE BIODIVERSIDADE - ICMBio. MINISTÉRIO DO MEIO AMBIENTE - MMA. Plano de Manejo da Área de Proteção Ambiental de Fernando de Noronha Rocas - São Pedro e São Paulo. Brasília:ICMBio. 2005.

INSTITUTO CHICO MENDES DE CONSERVAÇÃO DA BIODIVERSIDADE - ICMBio. MINISTÉRIO DO MEIO AMBIENTE - MMA. Estudo e determinação da capacidade de suporte e seus indicadores de sustentabilidade com vistas à implantação do plano de manejo da área de proteção ambiental do arquipélago de Fernando de Noronha. Brasília: ICMBio/MMA,2008. 
JACOBI, P.; TRISTÃO, M.; FRANCO, M. I. G. C. A função social da educação ambiental nas práticas colaborativas: participação e engajamento. Cad. CEDES, Campinas, v. 29, n. 77, p. 6379, Apr. 2009. Disponível em:<http://www.scielo.br/scielo.php?script=sci_arttext\&pid=S0101$32622009000100005 \& \operatorname{lng}=\mathrm{en} \& \mathrm{nrm}=\mathrm{iso}>$. Acesso em: 11 ago. 2020.

LIBÂNEO, J. C. Democratização da escola pública. A pedagogia crítico-social dos conteúdos. São Paulo: Edições Loyola, s/d.

LIMA, J. Nas Águas do Arquipélago de Fernando de Noronha.2000. 344 f. Tese (Doutorado em Antopologia) - Pontifícia Universidade Católica de São Paulo, Programa de Estudos de PósGraduação em Ciências Sociais, São Paulo, 2000.

LINSKER, R. Arquipélago de Fernando de Noronha. O paraíso do vulcão. 2 ed. São Paulo: Terra Virgem, 2011.

LÜDKE, M.; ANDRÉ, M.E.D A. A pesquisa em educação: abordagens qualitativas. São Paulo: EPU, 1986.

MOLL, J. (Org.) Educação integral: texto referência para o debate nacional. Brasília: MEC/SECAD, 2009. (Série Mais Educação).

MORIMOTO, Í. A. T. O.Direito e Educação Ambiental: Estimulo à Participação Crítica e à Efetiva Aplicação de Normas Voltadas à Proteção Ambiental no Brasil.2014.501. Tese (Doutorado em Ciência Ambiental) - Universidade de São Paulo, Programa de Pós-Graduação em Ciência Ambiental,São Paulo, 2014.

MORIN, E.Os sete saberes necessários à educação do futuro. 11 ed. São Paulo: Cortez; Brasília: UNESCO, 2006.

OLIVEIRA, H. T. de. Educação ambiental - ser ou não ser uma disciplina: essa é a principal questão?! In: MELLO, S. S. de.;TRAJBER, R. (Orgs.). Vamos cuidar do Brasil: conceitos e práticas em educação ambiental na escola. Brasília: MEC/MMA/UNESCO,2007. p. 103-114.

OLIVEIRA, C. G. A evolução da gestão sustentável dos meios de hospedagem de Fernando de Noronha.2015. 71p. Monografia (Pos-Graduação Lato Sensu em Gestao e Tecnologias Ambientais.) Universidade de São Paulo, São Paulo, 2015.

PERNAMBUCO. Estado. Constituição Estadual de Pernambuco, de 5 de outubro de1989. Recife: Câmara de Deputados, 1989.Disponível em:

<http://www.pe.gov.br/_resources/files/_modules/files/files_105_201111171514476bd8.pdf>. Acesso em: 11 ago. 2020.

PERNAMBUCO. Estado. Caderno de orientações pedagógicas para a educação ambiental: rede estadual de ensino de Pernambuco. Recife: Secretaria de Estado de Educação, 2013.

REIGOTA, M. Educação ambiental: fragmentos de sua história no Brasil. In: NOAL, F. O.; REIGOTA, M.; BARCELOS, V. H. de. L. (Orgs.).Tendências da educação ambiental brasileira. Santa Cruz do Sul: EDUNISC, 1998. p. 11-25.

ROCHA, M. L. Pesquisa-intervenção e a produção de novas análises. Psicologia, ciência e

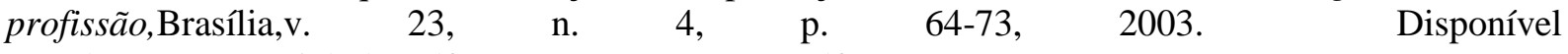
em:<http://www.scielo.br/pdf/pcp/v23n4/v23n4a10.pdf>. Acesso em: 11 ago. 2020. 
SAWAIA, B. B. Participação social e subjetividade. In: SORRENTINO, M. (Org.) Ambientalismo e participação na contemporaneidade. São Paulo: EDUC/FAPESP, 2001. p. 115-134.

SORRENTINO, M. Crise ambiental e Educação. In: QUINTAS, J. S. (Org.).Pensando e praticando a educação ambiental na gestão do meio ambiente. Brasília: MMA/IBAMA, 2000. p. 95-104.

SORRENTINO, M. Avaliação de processos participativos. In: SORRENTINO, M. (Org.) . Ambientalismo e participação na contemporaneidade. São Paulo: EDUC/FAPESP, 2001. p. 217-223.

TASSARA, E. Ambientalismo e participação na contemporaneidade: reflexões sobre o Ciclo de Seminários. In: SORRENTINO, M. (Org.) Ambientalismo e participação na contemporaneidade. São Paulo: EDUC/FAPESP, 2001. p. 210-216.

VALLES, M. Técnicas cualitativas de investigación social: reflexión metodológica y práctica profesional.Madrid: Síntesis, 1997.

VEIGA, A.; AMORIM, É.;COSSÍO, M. B. Um retrato da Presença da Educação Ambiental no Ensino Fundamental Brasileiro: o percurso de um processo acelerado. Brasília: MEC/INEP,2005.

VENERA,R. A. S.Sentidos da educação cidadã no Brasil. Educação em Revista, Curitiba, s/v, n. 34, p. 231-240, 2009. Disponível em: <http://www.scielo.br/scielo.php?script=sci_arttext\&pid=S0104$40602009000200014 \& \operatorname{lng}=\mathrm{en} \& n r m=\mathrm{iso}>$. Acesso em: 11 ago. 2020. 